\title{
OBSERVACIONES SOBRE EL ARCAÍSMO LINGÜÍSTICO DE LOS TEXTOS ALJAMIADO- MORISCOS
}

\author{
Mercedes Sánchez Álvarez*
}

Arabismo, en la sintaxis y en el léxico, en la fonética y en el sistema gráfico, dialectalismo, frecuentemente aragonés, y arcaísmo, son los rasgos caracterizadores de la lengua de los textos aljamiado-moriscos. Ya Ramón Menéndez Pidal en su estudio y edición del Poema de Yúçuf $f^{1}$ y Álvaro Galmés de Fuentes en las ediciones y análisis de manuscritos aljamiados por él realizadas, así como en estudios sobre aspectos lingüísticos de la literatura aljamiada pusieron de relieve estos hechos ${ }^{2}$. Trabajos y estudios posteriores de manuscritos aljamiados, editados e inéditos, vienen a corroborar la validez de la caracterización anteriormente establecida ${ }^{3}$.

* Universidad de Oviedo.

1. Advierte "el tinte más arcaico y dialectal que reviste siempre la literatura aljamiada en relación con la cristiana", Poema de Yúçuf. Materiales para su estudio, por Ramón MenÉNDEZ PIDAL, Universidad de Granada, 1952, p. 12 y el carácter de la lengua de las versiones de A y B "más popular que la que generalmente se usaba por los literatos aragoneses en las fechas respectivas", p. 65.

2. Historia de los amores de París y Viana. Edición, estudio y materiales, por A. GALMÉs DE FuENTES, CLEAM,1, Madrid, Gredos, 1970. El libro de las Batallas. Narraciones épico-caballerescas, 2 vols., por A. GALMES DE FuENTES, CLEAM,2, Madrid, Gredos, 1972, vol. 2, p. 25 y ss. Dichos de Los Siete Sabios de Grecia. Sentencias morales en verso, por A. GALMÉS DE FuENTES, CLEAM, 8, Madrid, Gredos, 1970. A. GALMÉS DE FUENTES, "Interés en el orden linguiústico de la literatura aljamido-morisca», Actes du X Congrès International de Linguistique et de Philologie Romanes (Strasbourg, 1962), París, Klincksieck, 1965, vol. 2, pp. 527-546.

3. Se remite aquí a las páginas de ediciones de textos aljamiados, como los de la Colección de literatura española aljamiado-morisca (=CLEAM), que contienen referencia expresa a estos hechos; o bien a otras ediciones en las que se describe la lengua del texto editado seleccionando formas concurrentes, o una muestra del léxico que resulta indicativa. Omito, por no hacer demasiado extensa esta nota, la mención de estudios específicos sobre vocabulario o notas sobre el léxico, que pueden considerarse incluidas, como fuentes documentales o bibliográficas del Glosario de voces aljamiado-moriscas de A. GALMÉs DE FuenTES, M. SÁNCHEZ Álvarez, A. Vespertino Rodrícuez y J. C. Villaverde Amieva, Oviedo, Fundación Menéndez Pidal, 1994. Puede hallarse información sobre estos temas en los repertorios bibliográficos de Aljamia, Boletín de información bibliográfica. Mudéjares-moriscos-Textos Aljamiados-Filología Arabo-Románica, Oviedo, nos. 1-6, 1989-1994, y Luis Fernando Bernabé PONS, «Bibliografía 
Me propongo en este trabajo reflexionar sobre uno de estos rasgos, el arcaísmo lingüístico. Es un hecho comprobado la tendencia al arcaísmo que muestran las versiones aljamiadas de textos de origen occidental, como es el caso de París y Viana o Dichos de los Siete Sabios ${ }^{4}$, donde cobra especial fuerza probatoria, y en proporciones variables ha sido señalado por los estudiosos de textos aljamiados.

El arcaísmo se viene estableciendo por la presencia de rasgos que se detectan en el plano fónico, que suponen soluciones conservadoras, que, si bien, no son privativas de la literatura aljamiada, se dan en ésta con una frecuencia significativamente más elevada que en la de sus coetáneos cristianos. Aunque las soluciones innovadoras de la época no son tampoco desconocidas en la lengua de estos textos, lo que origina un gran número de variantes léxicas por razones fónicas, le confiere un tono arcaizante notable. Otros rasgos, deducidos del análisis sintáctico, han sido preferentemente explicados a partir de la influencia de la sintaxis árabe, patente en los textos que, con frecuencia, siguen modelos en lengua árabe.

Se explica el arcaísmo por el alejamiento de los moriscos de la norma culta y cortesana y por la mayor espontaneidad de la lengua que presentan los textos aljamiados 5 ; por el aislamiento cultural de la comunidad islámica respecto del grupo dominante, la no participación por parte de los moriscos en los ideales lingüísticos del Renacimiento, y la no adopción de cultismos procedentes del latín e italiano ${ }^{6}$. O. Hegyi propone, también, la interpretación del apego al arcaísmo como un mecanismo de defensa, en el intento de

de la literatura aljamiado-morisca», Xarc Al-Andalus, vol. 5, Universidad de Alicante, 1992. Cinco leyendas y otros relatos morisos (ms. 4953 de la Biblioteca Nacional de Madrid), edición, estudio y materiales, por Ottmar HEGXI, CLEAM, 4, Madrid, Gredos, 1984, pp. 21-22. El manuscrito misceláneo 774 de la Biblioteca Nacional de París (Leyendas, itineraios de viajes, profecías sobre la destrucción de España y otros relatos moriscos), edición, estudio y glosario, por Mercedes SÁNCHEZ ÁlvAREZ, CLEAM, 5, Madrid, Gredos, 1982, pp. 69-75. Leyendas aljamiadas y moriscas sobre personajes bîblicos, Introducción, edición, estudio lingüístico y glosario, por Antonio VeSPERTINo ROdRÍGUEz, CLEAM, 6, Madrid, Gredos, 1983, pp. 71-80. El libro de las suertes. Tratado de adivinación por el juego de azar, Estudio, edición y glosario por Karl I. KOBBERVIG, CLEAM, 7, Madrid, Gredos, pp. 37-39. La plegaria musulmana en el "Compendio de Al-Tulaytuli". Transcripción del manuscrito de Sabiñán (Zaragoza), por María José CERVERA FrAS, Institución Fernando el Católico, Zaragoza, 1987, pp. 39 y 77-86. Relatos Píos y Profanos del ms. aljamiado de Urrea de Jalón, por Federico CoRrienTE, prólogo de M. ${ }^{a} \mathrm{~J}$. Viguera, Institución Fernando el Católico, Zaragoza, 1990, pp. 39 y 77-86. El Cántico islámico del morisco hispanotunecino Taybili, Luis F. BERNABÉ PONS, Institución Fernando el Católico, Zaragoza, 1988, pp. 76-79. Libros de dichos maravillosos (misceláneo morisco de magia y adivinación), Introducción, glosarios e índices, por Ana LABARTA, Consejo Superior de Investigaciones Científicas, Instituto de Cooperación con el Mundo Árabe, Madrid, 1993, 3. 1., p. 0.7 y pp. $205-210$.

4. París y Viana, op. cit., pp. 25-34; Dichos, op. cit., p. 79 y pp. 80-84.

5. París y Viana, op. cit., pp. 25-34; Batallas, op. cit., v. 2, pp. 25-34; Dichos, op. cit., pp. 79-84.

6. Cinco Leyendas, op. cit., pp., 21-22. 
preservar la propia identidad cultural, y un rasgo típico de la mentalidad de la aljama ${ }^{7}$.

Sin pretender establecer deducciones sobre la lengua oral, en la lengua escrita, el arcaísmo se detecta en los siguientes rasgos, de los que enumeraré, de forma abreviada, los más frecuentes 8 :

Persistencia de /f-/inicial, aunque coexistiendo con la solución aspirada $\mathrm{h}$-/ o el enmudecimiento, que da lugar a formas concurrentes que reflejan este cambio, como fablar- hablar; façer- haçer- açer; fallar-hallar-allar; fartarharto; fazienda- haçienda- azienda; façedor- haçedor; fecho- hejo; fender- hender; ferimiento- herimiento; fijo- hijo- ijo(s); finkar- hincar; formiga- hormiga; fuelgohuelgo, o casos de $h$-inorgánica hazedo- açedamiento; hedat- edad; heos; heredança; herror, hierro(s)-errada, yerro ${ }^{9}$, etc. Para la determinación de valores fónicos son de particular interés los textos escritos en caracteres árabes, por los grafemas utilizados correspondientes a la [fä’'] y [hā'], fricativa, labiodental, y fricativa, laríngea, sorda o sonora, respectivamente.

La representación de grupos consonánticos, $b d, b t, b k$ no simplificados, con los que también concurren las soluciones modernas, así adebdeçer-adeudeçido; bebdo(s)- beudo; cabdillo- caudillo; çibdad-çiwdad-çiydad; kobdo-kowdo; debdo- dewdo-débito (de carácter culto); rrebtar- rrewtar-rribtar- rriwtar; rrevibkar- rrebiwkar, etc.

Otros, como la conservación de /d/ en la desinencia de la $2^{\mathrm{a}}$ pers. del plur. (lat.<-atis) en las formas verbales; o ad ( $3^{\text {a }}$ pers., sing., pres., ind. de haber) utilizada como auxiliar ante participio que comience por vocal; o vido ( $3^{a}$ pers., sing., perf.s., de ver) que alterna con las soluciones $\sin / d /$. Las frecuentes fluctuaciones de las formas de futuro, y la conservación de futuros apocopados sin epéntesis consonántica del tipo salrrá, verná- benrá- konverná (éstas con transportación de la consonante), y otras sin apócope, o con epéntesis como salliré, combrá, etc. que no llegan a hacerse generales.

Las arcaizantes so; estó ( $1^{a}$ pers., s., pres., ind. de ser, estar), o las formas pronominales sin refuerzo como nos, vos, o la de valor posesivo nuesso, vuesso, la copulativa $e$, o las arcaizantes ansi; agora; mesmo; nengún, $-0,-a$; do, etc. Todas ellas frecuentes en los textos aljamiados y consignadas habitualmente en los glosarios y estudios de la lengua de los textos.

Sin embargo, la consideración del arcaísmo en textos aljamiados creo que presenta algunos problemas de análisis e interpretación, relacionados, en parte, con la dificultad de delimitar el criterio de arcaísmo aplicado a una literatura situada cronológicamente en los siglos XV-XVI y comienzos del

\footnotetext{
7. Ibidem.

8. Véanse referencias de las notas 2 y 3.

9. Ejemplos tomados del Glosario de voces aljamiado-moriscas.
} 
XVII, que hunde sus raíces en la etapa mudéjar ${ }^{10}$ en la que se redactan algunas obras muy representativas, y se establece el sistema gráfico para la fijación de la lengua escrita, que además, se transmite de forma manuscrita, con abundante reproducción en copias, lo que podría favorecer la pervivencia de formas anteriores a las más usuales en la fecha de la copia y la proliferación de variantes. Un período muy importante, que revaloriza el interés de la literatura aljamiada para la deducción de hechos lingüísticos, por coincidir con la época en la que se producen los cambios que van a comprometer el funcionamiento del sistema medieval del castellano ${ }^{11}$, pero, quizá, no tan dilatado como para permitir ver reflejados en su totalidad la amplitud de los mismos y una nueva reacomodación al sistema gráfico.

Si consideramos que el español de la época aludida, en palabras de Rafael Lapesa, "mucho más seguro que el de la Edad Media, era sin embargo, un idioma en evolución muy activa. El concepto de corrección lingüística era más amplio que en los períodos posteriores, y entre el vulgarismo y las expresiones admitidas no mediaban límites tajantes. Con todo, hubo en los siglos XVI y XVII una labor de selección entre sonidos, formas y giros coincidentes, que condujo a una considerable fijación de usos en la lengua literaria"12 y, puesto que tampoco entre los autores cristianos los gustos y preferencias idiomáticas eran coincidentes, la comparación global con autores cristianos de la época se hace dificultosa. Menéndez Pidal señala que "el lenguaje, la vida cultural del siglo XVI, no es como una llanura"13. Ni la división por siglos, ni por generaciones nos ordenan los hechos del lenguaje, "más debemos atender a la convivencia de varias [generaciones] y a la resultante de las corrientes que promueven, siempre sometidas a la inducción de las unas por las otras"14. En la regulación de una norma para la lengua literaria tuvo una gran importancia el desarrollo de la imprenta que redujo en la reproducción de un texto en textos impresos las múltiples variantes de la tranmisión manuscrita, y eliminó pronto rasgos dialectales. El aragonés durante los últimos años del XV estaba aún muy arraigado en su territorio y en Zaragoza, importante centro de producción tipográfica, todavía hacia 1500 ,

10. Véase Míkel DE EPALZA, «A modo de introducción, el escritor Ybrahim Taybili y los escritores musulmanes aragoneses», en Luis F. BERNABÉ PONS, op. cit., pp. 5-30; A. VESPERTINO RODRícuez, «La datación de los manuscritos aljamiado-moriscos», Estudios Románicos. Homenaje al profesor Luis Rubio II, Murcia, Universidad de Murcia, V (1987-88-89), pp. 14191439; María J. Viguera, «Introducción» en Federico CORRIENTE CORDOBA, op. cit., pp. 9-51; Míkel de EPALZA, Los moriscos antes y después de la expulsión, Madrid, Mapfre, col. El Magreb, 1992, pp. 52 y ss.

11. A. GALMES DE FuENTES, «Interés en el orden lingüístico...».

12. Rafael LAPESA, Historia de la Lengua Española, Madrid, Gredos, 1980, XIII, p. 367.

13. Ramón MenÉndez PIDAL, La lengua de Cristóbal Colón, "El lenguaje del siglo XVI", Madrid, Espasa Calpe, S. A., col. Austral, 1968, $5^{\text {a }}$ ed., p. 84.

14. Ibidem, p. 47. 
la imprenta no uniformaba la lengua de los libros de los autores aragoneses, si bien, pronto fueron adhiriéndose a las modalidades castellanas ${ }^{15}$.

Por lo que afecta al sistema fonológico, desde la perspectiva actual se puede afirmar "con casi unánime acuerdo, que durante el XVI y el comienzo del XVII se difunde en la lengua literaria una norma nueva[...]. En parte, se trata del abandono de las normas toledanas que habían prevalecido hasta el XVI, y de la adopción, por los cortesanos y los cultos, de la norma castellana vieja"16. Pero fue un proceso paulatino en el que habría que diferenciar datos locales y cronológicos, y no debió producirse uniformemente en todas las comarcas, a diferencia del cambio fónico que no tiene esta gradualidad, sino que es sustitución de un tipo fónico por otro, con el que coexiste durante un largo período ${ }^{17}$.

La referencia, pues, a los autores cristianos, sin más especificación, resulta algo imprecisa y compleja, por la falta de uniformidad, sobre todo si consideramos que muchos de los arcaísmos que hemos indicado pueden hallarse en autores cristianos, inclusive en obras impresas, o son objeto de preferencia o rechazo por parte de los gramáticos y tratadistas de la lengua de la época, así por ejemplo:

agora, Juan de Valdés la emplea en el Diálogo de la lengua. En el XVII alterna con ahora. Juan F. de Ayala Manrique (1693): “No ay duda que [agora] está bien dicho en castellano, y assí lo han usado autores muy cultos; pero ya se tiene por palabra anticuada, y dezimos aora, quitada la $g^{\prime \prime 18}$, Autoridades, s.v. todavía constata su empleo: "aunque muchos escriben aora y agora, es más propio ahora, que es como decir a esta hora"19.

ansí, Es frecuente y popular en toda la Edad Media y Siglo de Oro. La preferencia de Valdés por así se argumenta por "el uso de los que escriben bien", y también por el origen del vocablo ${ }^{20}$; Santa Teresa la emplea, y Autoridades,s.v. la registra como "voz de poco uso en lo moderno" y la documenta en Sta. Teresa, D. Gabriel del Corral y Alvarez Gómez de Ciudad Real.

mesmo, La vacilación entre mismo y mesmo permanece aún en el lenguaje popular $^{21}$, mismo era forma menos usual, sobre la que se formó el superlati-

15. Ibidem, p. 51.

16. Emilio Alarcos LLORACH, «De nuevo sobre los cambios fonéticos del siglo XVI», Actas del I Congreso Internacional de Historia de la Lengua Española, Madrid, Arco Libros, 1988, vol. 1, pp. $47-59$.

17. Ibídem.

18. La cita está tomada de Manuel Alvar y Bernard Potter, Morfología Histórica del Español, Madrid, Gredos, 1983, pp. 334-335.

19. Diccionario de Autoridades, ed. facsímil, Real Academia Española, Madrid, Gredos, reimpr. $1976=$ Autoridades.

20. Diálogo, op. cit., p. 179.

21. Federico HANSSEN, Gramática Histórica de la Lengua Castellana, Buenos Aires, Librería y Editorial "El Ateneo", 1945, p. 85. 
vo22; Autoridades, s.v. mismo "viene del italiano medessimo por cuya razón se dize igualmente mesmo. Mismo se hará dominante en el lenguaje ciudadano a partir del XVII y desde el XVIII queda relegada al habla rural ${ }^{23}$.

nengún,-o,-a, Siguió empleándose en el XV. Todavía aparece en el Diálogo de la Lengua de Valdés, si bien quizá debido a los tipógrafos ${ }^{24}$.

e, Cobarruvias, s.v.:"Vale por la letra Y copulativa, como Pedro e Juan, y con algún primor usamos della quando la dicción que le sigue empieça en $i$, como María e Inés". Este uso, que coincide con el preferido por Valdés ${ }^{25}$, se generalizó en el XVI ${ }^{26}$.

do, Sobrevive en el estilo poético y se emplea como variante en Nebrija, y en Celestina y El Quijote27.

nueso, vueso, A. Saroïhandy da estas formas como usuales en Alto Aragón ${ }^{28}$. Se emplean en El Quijote ${ }^{29}$; en el Diálogo de la lengua Coriolano hace a Valdés la observación: - "A donde scrivís vuestra con $r$, y no siento que la pronunciáis sino con $s$, diziendo vuessa" a lo que Valdés responde:-[...].; porque si diziendo $v . m$. pronunciasse el vuestra con $r$, cualquier castellano que me oyese juzgaría que soy estrangero [...]. Es bien verdad que la pronunciación más ordinaria es $\sin r^{\prime \prime 30}$.

vos, Cobarruvias, s.v. "pronombre primitivo, de la segunda persona del plural, aunque usamos del en singular [...]".

nos, Cobarruvias, s.v.nosotros "es lo mismo que nos, pronombre plural de primera persona, quasi nos alteri".

so, Valdés constata su uso, que rechaza en la prosa, no en el verso: "[.]yo so por yo soy dizen algunos, pero aunque se pueda dezir en metro, no se dize bien en prosa" 31 . Todavía a mediados del siglo XVI se encuentran ejemplos ${ }^{32}$.

22. Manuel Alvar y Bernard Portier, op. cit., p. 109.

23. J. Corominas y J.A. PASCual, Diccionario crítico etimológico castellano e hispánico, 6 vols., Madrid, $1980-1991=D C E C H$

24. DCECH, s. v. no.

25. Sebastián DE COBARRuvias, Tesoro de la lengua Castellana o Española. Primer Diccionario de la Lengua (1611), ed. Turner, Madrid-México, 1984 =COBARRUVIAS.

26. Manuel Alvar y Bernard PotTier, op. cit., p. 352.

27. $D C E C H$.

28. Federico HANSSEN, op. cit., p. 80.

29. M. Alvar y B. Potmer, op. cit., p. 100.

30. Diálogo, op. cit., p. 184.

31. Ibídem, p. 130.

32. Federico Hanssen, op. cit., p. 103; M. Alvar y B. Pottier, op. cit., p. 225. 
vido, Además de que las formas que retienen $/ d /$ se encuentran en aragonés y podrían explicarse por dialectalismo, vido, vide, sobreviven en las hablas rurales de España y en judeoespañol ${ }^{33}$.

Respecto a otros rasgos, como la conservación de grupos gráficos, $b d, b t$, $b k$ que da lugar a las numerosas variantes léxicas de este origen, ya aludidas, tampoco presentan una solución uniforme en los autores cristianos de la época. Nebrija, sin aplicar un criterio uniforme, los mantiene en unos casos, y los suprime en otros ${ }^{34}$; Valdés, en cambio, prefiere su conservación, como refleja el fragmento del Diálogo de la lengua que reproduzco a continuación: Marcio. -"Veo en vuestras Cartas, que en algunos vocablos ponéis $b$ adonde otros no la ponen, y dezís cobdiçiar, cobdo, dubdar, subdito. Querría saber ¿por qué lo hazéis assí? Valdés.- Porque a mi ver los vocablos están más llenos y mejores con la $b$ que sin ella, y porque toda mi vida los he scrito y pronunciado con $b^{\prime \prime 35}$.

Las formas de futuro sincopadas y otras, como las que daban lugar a la alternancia en el lexema verbal de la alveolar, vibrante, simple y múltiple; o las que no desarrollaban una consonante de ligazón entre $/ m^{\prime} r /, / n^{\prime} r /, l^{\prime} r /$ dieron lugar a anomalías que fueron también objeto del intento de normalización por parte gramáticos y tratadistas, $\mathrm{y}$, aunque muchas entraron en desuso en el XVI, no se realizó una absoluta regularización en la lengua moderna ${ }^{36}$. Respecto a la /d/ desinencial en la $2^{2}$ pers. del plural (lat.<-atis), la supresión de ésta en las formas graves es general en el XV, pero en las esdrújulas se conserva hasta el XVII ${ }^{37}$.

Respecto a la /f-/ de empleo muy frecuente en los textos aljamiados, que también alterna con $h-\%$ o cero fónico, como ya hemos ejemplificado. De nuevo no hallamos ante la falta de uniformidad en las soluciones romances peninsulares durante los siglos XV y XVI y en los textos de autores cristianos, más, si consideramos la presencia de aragonesismos frecuentes, y el origen aragonés de muchos manuscritos. En Aragón la conservación de /f-/ fue casi general, solo a partir de 1518 empiezan a darse las formas con $h$ en la capital $^{38}$. El habla toledana mantenía un sonido aspirado que en la ortografía representaba por $h$ y la aspiración será norma del idioma literario durante el XVI pero, ya desde antes, su pérdida en la Castilla burgalesa se expande a oriente y occidente sobre las áreas medias del leonés y aragonés ${ }^{39}$. Durante

33. M. Alvar y B. PotTier, op. cit., pp. 116-117.

34. Antonio DE NeBriJA, Reglas de Orthographía en la lengua castellana, Estudio y edición de Antonio QuiLIS, Bogotá, Publicaciones del Instituto Caro y Cuervo, XL, 1977, pp. 97-98.

35. Diálogo, op. cit., p. 168.

36. M. Alvar y B. Pottier, op. cit., pp. 245-252.

37. Federico HANSSEN, op. cit., p. 198.

38. Manuel Alvar, El dialecto aragonés, Madrid, Gredos, 1953, pp. 156-164.

39. Emilio Alarcos Llorach, El español, lengua milenaria, Valladolid, Ámbito, 1982, p. 67 y ss.; Francisco Delicado (Prohemio a su edición del Amadís. Venecia, 1533) resuelve que "los vo- 
la primera mitad del XVI se impone en la corte. Todavía en la primera mitad del siglo XVI se toleraba la $f$ arcaizante de fijo, fincar, fecho, etc. y entre los notarios y leguleyos se atestigua a lo largo del XVII ${ }^{40}$. Numerosas son las referencia a esta vacilaciones en el Diálogo de la lengua: Marcio.-"[...] ¿qué es la causa porque vos escrivís con $h$ casi todos los vocablos que el latino escrive con $F$ ? Y sabed que lo que hace estar más maravillado desto, es ver que muchos castellanos escriven con $f$. Valdés.- [...] torno a dezir que de la pronunciación aráviga ${ }^{41}$ le viene a la castellana el convertir la $F$ latina en $h$; de manera que, pues la pronunciación es con $h$, yo no sé por qué ha de ser la escritura $\operatorname{con} f$, siendo fuera de propósito que en una lengua vulgar se pronuncie de una manera y escriva de otra; yo siempre he visto que usan $h$ los que se precian de scrivir el castellano pura y castellanamente; los que ponen la $f$ son los que no siendo muy latinos, van trabajando de parecerlo" 42 .

Todas estas posibilidades se aprecian como formas concurrentes en los textos aljamiados, con predominio de $f$ - ¿por arcaísmo dentro de la propia tradición escrituraria?, ¿por dialectalismo?

Pero, junto a esta inestabilidad, hay algunos textos en los que las grafías, coincidentes con la situación moderna -aunque no, lógicamente con su regulación ortográfica, que es norma posterior a la época tratada-, parecen reflejar la fijación del cambio $/ f />/ h />0$. Así en el ms.Gay.T.18, R.A.H., fols. 189v.$193 v^{43}$, que contiene una versión del s. XVI de un texto compuesto probablemente dos siglos antes y [Poema en alabanza de Mahoma], $f$-aparece en falta, fiel, fin, fuego, fuerte, fuesa (condiciones fónicas, y casos, en que se conserva modernamente en español) y $h$ - en hablar, habló, hablase, hablaba, hablado, hermosa, hermosura, deshaciendo (con pref. des-), hagamos, haziendo, haga, hartar, halla, halló, hallados, hagamos, hijo (casos en que hoy es cero fónico) pero que sin duda es aspirada en el texto pues está representada por [hā'] como el arabismo, que también figura en el texto hardacho. No resultaría esta solución diferente a la propugnada por Valdés, o la que refleja Garcilaso de la Vega en

cablos con que con $h$ y con $f$ se escriven, que assí los dexamos porque todos están y pueden estar" y expone algunos ajemplos: "hijo es más elegante por ser toledano, y fijo está bien por ser sacado del latín". (La cita está tomada de GONZÁlEZ OlLÉ, "Aspectos de la norma lingüística toledana», Actas del I Congreso Internacional de Historia de la Lengua Española, Cáceres, Madrid, Arco Libros, 1988, vol. 1, pp. 859-871, especialmente p. 869.

40. Rafael LAPESA, op. cit., p. 368.

41. Nebrija coincide con Valdés en el error de considerar de origen árabe la aspiración de /f-/ latina, ver Antonio DE NEBRIJA, op. cit., p. 128.

42. Diálogo, op. cit., p. 147 .

43. Descrito por Eduardo SaAvedra Moragas, Discursos leídos ante la Real Academia Española en la recepción pública el 29 de Diciembre de 1878, Madrid, 1978, p. 167, incluido en George TICKNOR, Historia de la literatura española, vol. IV, pp. 327-339. Como base de las referencias al cambio $/ f-/ / h-/$ parto de la edición y estudio realizados por Toribio FUENTE CORNEJO, Poesía religiosa aljamiado-morisca, Oviedo, 1985, en prensa. 
Ode ad florem Gnidi (Canción $V)^{44}$, pese a que el poeta morisco versifica en cuaderna vía de versos alejandrinos, cuyo lenguaje, obviamente, moderniza la copia del XVI a la que aludo.

En el ms.J.LII, fols. 576r.- 578v. ${ }^{45}$ que contiene [Coplas en albanza de Al.lah], f- sólo aparece en fuente, fuego, firmamento, favoreçer, fuerça, fe, favoreçidos (cuya $f$ - se mantiene en la actualidad) y ningún signo gráfico detecta valor fónico alguno en allemos, izistes, azes, açnos, iguales en la grafía a aber, abrán, que, creo, se puede interpretar como indicio de que no se practica la aspiración, pues la aspirada, representada por la [hä'] corresponde a las formas del verbo halaqar, de carácter híbrido, cuyo lexema procede del árabe, y al sustantivo Al.lah.

En estos textos de contenido islámico, un panegírico del profeta Muhammad y alabanzas de Al.lah, en cuaderna vía de versos alejandrinos y en coplas de arte menor respectivamente, el soporte rítmico y métrico los inserta en la tradición literaria romance. Muy similar es la distribución de $f$ - y $h$ - en el $m s . n^{0} .6 .016$ B.N.M que contiene una versión, en caracteres latinos del texto de Iça Chebir, escrito en 1462, ms. $n^{\circ} 6.016$ de la Biblioteca Nacional de Madrid ${ }^{46}$, en él, la distribución $f$ - y $h$ - evidencian lo excepcional de la conservación de $f$-, frente al empleo generalizado de $h$ - cuando corresponde a $/ f-/$ latina, y, muy frecuente el empleo de $h$-inorgánica.

En la elaboración de glosarios y léxicos que aclaran y completan la edición de textos aljamiados, el arcaísmo suele quedar bien reflejado, por ser éste uno de los rasgos que intervienen en el criterio de elaboración, pero podría dar una impresión hipercaracterizadora si no se contrasta con las soluciones modernas y la frecuencia con que éstas ocurren en los textos. En este sentido me parece ilustrativo reflejar los datos que ofrece el estudio del vobulario del ms. 4.871, B.N.M. ${ }^{47}$ : agora, 11 oc.- aora, 24 oc.; ansi, 3 oc.- así, 130 oc.; mesmo, es de uso general; do, 10 oc.- donde, 145 oc.; nuestro, es de uso general; vuestro, es general; so, 1 oc.-soy, 113 oc.; estoy, es general; vido, 3 oc.- vio, 66; os, es general.

Más estable parece la conservación de grupos gráficos $b d, b t, b k$ en $a d e b-$ dedeçer, bebdo(s), çibdad, cobdo, debdo(s), rebtar-ribtar-riebto, revibkar son conser-

44. Rafael Cano Agullar, Análisis filológico de textos, Madrid, Taurus Universitaria, 1991, pp. 116-129.

45. Julián RiBera y Miguel Asin, Manuscritos árabes y aljamiados en la Biblioteca de la Junta, Madrid, 1912, p. 191; referencias extraídas de Toribio FuENTE CORNEJo, op. cit.

46. Taoufik Limam, Edición, estudio linguístico y glosario del ms. morisco no. 6.016 B. N. M., Tesis Doctoral defendida en la Universidad Complutense de Madrid, Dpto. de Filología Románica, Madrid, 1994, dirigida por Álvaro Galmés de Fuentes.

47. Juan Carlos Busto CortinA, El alkitāb de Çamarqandĩ. Edición del ms. aljamiado 4. 871 de la B. N. M., con un vocabulario completo y un estudio de algunos cuentos que en él aparecen, Tesis doctoral defendida en la Universidad de Oviedo, Dpto. de Filología Clásica y Románica, 1991, dirigida por Álvaro Galmés de Fuentes. 
vados, y mayoría en los casos en que existen formas concurrentes que los simplifican: cabdillo, 4 oc.- cawdillo 1 oc.; dubda 7 oc.- duda 1 oc.; dubdoso,-os, -as 13 oc.- dubdosa(s) 1 oc.; cobdiçiar 38 oc.- codiçiar 4 oc.; cobdiçia(s) 47 oc.- codiçia 6 oc.; debda(s) 8 oc.- dewdas 3 oc.

Las formas de futuro ofrecen la heterogeneidad formal propia del castellano de la época: si el futuro de salir presenta mayoría con apócope: salré, 1 oc; salrás, 3 oc.; salrá, 17 oc.; salrán, 10 oc., que son concurridas con las que generalizan epéntesis consonántica, saldrá, 4 oc.; saldremos, 1 oc. saldréys, 2 oc.; el futuro de venir invierte la proporción frente verná, que aparece e 3 ocurrencias, vendré, 4 oc.; vendrás, 2 oc.; vendrá, 56 oc.; vendremos, 3 oc.; vendrán, 14 . y el de tener siempre generaliza la consonante de ligazón: tendrá, 3 oc.; tendréys 3 oc.; tendrán, 1 oc.

Respecto a $/ f-/ / h-/$, todavía no parece definitivamente fijado este cambio. La frecuencia de empleo de $f$ - en las diferentes formas de la flexión de fazer es superior a la de formas $\sin h$-, aun así, se registran variantes de hazer en 234 oc.; fijo es prácticamente general, con la excepción de hijo que ocurre en una ocasión. También son más frecuentes fermoso, - $a,-0 s,-a s, 22$ oc.; fermosura 16 oc.; fondo, 4 oc.; formigas 4 oc.; fuelgo, 4 oc.; fuir, 28 oc., aunque concurren con hermoso, 19 oc.; hermosura 12 oc.; honda 1 oc.; hormiga 1 oc.; huelgo 1 oc.; huir 13 oc. Inversa proporción, en cambio, ofrecen las formas con $h$ - en hablar, 98 oc.; habla(s), 16 oc.; hallar, 144 oc.; hartar, 12 oc.; hurtar, 11 oc. junto a fablar 44 oc.; fablamiento 3 oc.; hallar, 5 oc.; hartar 1 oc.; furtos 3 oc.

El registro de un vocabulario totalizador de la lengua del texto parece que podría relativizar el matiz arcaizante de la misma, ya que, la frecuencia de aparición de formas concurrentes pone de manifiesto que también en él se inicia, o está en vía el desuso.

A falta de referencias cronológicas fiables sobre la transmisión y fecha de elaboración de los textos, y de versiones paralelas con autores cristianos, sería, quizá, conveniente discriminar más este aspecto del arcaísmo en la literatura aljamiado-morisca y contrastar con otros niveles de lengua, pues, es probable que entre los moriscos -como entre los autores cristianos de este período, ss. XV al XVII- no haya tampoco idénticas preferencias ni una uniformidad de estilo. 